\title{
Specific safety and tolerability considerations in the use of anticonvulsant medications in children
}

This article was published in the following Dove Press journal:

Drug, Healthcare and Patient Safety

I June 2012

Number of times this article has been viewed

\author{
Amy Z Crepeau' \\ Brian D Moseley² \\ Elaine CWirrell ${ }^{3}$ \\ 'Division of Epilepsy, Department of \\ Neurology, Mayo Clinic, ${ }^{2}$ Department \\ of Neurology, Mayo Clinic, ${ }^{3}$ Divisions \\ of Epilepsy and Child and Adolescent \\ Neurology, Mayo Clinic, Rochester, \\ MN, USA
}

\begin{abstract}
Epilepsy is one of the most common neurological disorders in the pediatric age range, and the majority of affected children can be safely and effectively treated with antiepileptic medication. While there are many antiepileptic agents on the market, specific drugs may be more efficacious for certain seizure types or electroclinical syndromes. Furthermore, certain adverse effects are more common with specific classes of medication. Additionally patient-specific factors, such as age, race, other medical conditions, or concurrent medication use may result in higher rates of side effects or altered efficacy. Significant developmental changes in gastric absorption, protein binding, hepatic metabolism, and renal clearance are seen over the pediatric age range, which impact pharmacokinetics. Such changes must be considered to determine optimal dosing and dosing intervals for children at specific ages. Furthermore, approximately one third of children require polytherapy for seizure control, and many more take concurrent medications for other conditions. In such children, drug-drug interactions must be considered to minimize adverse effects and improve efficacy. This review will address issues of antiepileptic drug efficacy, tolerability and ease of use, pharmacokinetics, and drug-drug interactions in the pediatric age range.
\end{abstract}

Keywords: antiepileptic drugs, drug-drug interactions, pharmacokinetics

\section{Introduction}

New-onset epilepsy affects approximately 45 per 100,000 children per year, ${ }^{1,2}$ making it one of the most common neurological disorders in the pediatric age group. The majority of these children will be initiated on antiepileptic drugs (AEDs). While most respond favorably to their first medication, approximately one third will have persistent seizures, and are often exposed to multiple agents. Furthermore, AEDs are frequently used in children for conditions other than epilepsy, including mood disorders and headache.

The goal of antiepileptic medication is to achieve seizure freedom, and thus minimize the comorbidities associated with epilepsy, such as injury, sudden unexplained death in epilepsy, intellectual disability, and behavioral problems. Several factors are considered when choosing which of the many AEDs available would be the best choice for a specific child. These factors include efficacy, tolerability and ease of use, pharmacokinetic issues and, if the child is on other medications, drug-drug interactions. The goal of this review is to address each of these factors, with specific emphasis on the pediatric age range.

\section{Efficacy and Effectiveness}

The "efficacy" of a drug refers to its ability to achieve a therapeutic effect under ideal circumstances (ie, in a medical trial) whereas "effectiveness" refers to the therapeutic 
effect seen in the real world. Efficacy is usually assessed by drug licensing studies, where a medication or placebo is added on to the patient's current medication regimen, and the patient is then followed to assess seizure frequency. Many medications never undergo formal drug trials in children, and their use is based on extrapolation of adult data. Trials which focus specifically on the pediatric age range are generally only done after a medication has been proven safe and effective in adults.

Furthermore, in licensing trials, a medication is compared to placebo, which is helpful to determine efficacy. In real life, when commencing a child on antiepileptic medication, the decision to treat has already been made. We want to know whether drug " $x$ " is more efficacious than drug " $y$ " to inform "best treatment." Unfortunately, such comparative efficacy studies are very rare in epilepsy, and particularly in pediatric epilepsy.

Epilepsy is a clinical diagnosis which is made in the context of the patient's history, physical examination, and ancillary tests. In pediatrics, the rate of misdiagnosis is high, studies have shown that one quarter to one third of children diagnosed with "seizures" probably do not truly have epilepsy. ${ }^{3-5}$ Thus, confirmation of diagnosis is essential prior to initiation of AEDs. Furthermore, epilepsy is not a single disorder, but rather describes a diverse group of seizure types, and an even more diverse group of etiologies. The revised classification of epilepsy has recently been published, ${ }^{6}$ and epilepsy is classified on several levels including:

1. Mode of onset
a. Generalized or bihemispheric
b. Focal or unihemispheric
c. Unknown/spasms

2. Etiology
a. Genetic or presumed genetic
b. Structural or metabolic
c. Unknown

3. Electroclinical syndrome or constellation.

Accurate classification of a child's epilepsy is critical to choosing the most appropriate medication. Specific AEDs may be particularly effective in certain seizure types or electroclinical syndromes, but may make others worse.

\section{Choosing the most efficacious AED for most cases of childhood epilepsy}

With the exception of relatively rare electroclinical syndromes where there is a clear "best" treatment, in most children with epilepsy several equivalent choices are available. ${ }^{7,8}$ Overall there is a paucity of well-designed, properly conducted, randomized controlled studies to inform "best treatment" of children with epilepsy. ${ }^{8}$ Commonly used AEDs for specific seizure types/electroclinical syndromes are listed in Table 1.

For West syndrome, adrenocorticotropic hormone (ACTH) has been shown to be superior to lower dose hydrocortisone for control of spasms, ${ }^{9}$ but equivalent to high-dose prednisolone. ${ }^{10}$ High- and low-dose ACTH regimens were equivalent, with greater hypertension with high doses. ${ }^{11,12}$ In the absence of tuberous sclerosis, ACTH was more effective than vigabatrin in one study, ${ }^{13}$ and either ACTH or high-dose prednisolone more effective than vigabatrin in another. ${ }^{10}$ High-dose vigabatrin was found to be more effective than low-dose vigabatrin. ${ }^{14}$ For West syndrome due to tuberous sclerosis, vigabatrin is considered the drug of choice, with several studies documenting its superiority over ACTH or hydrocortisone. ${ }^{13-16}$ In addition to improved control of spasms, one study found significant improvements in developmental quotient in seven children with tuberous sclerosis receiving vigabatrin for infantile spasms, suggesting that early use of vigabatrin might improve intellectual and behavioral outcomes. ${ }^{17}$

Table I Antiepileptic medications commonly used in children based on seizure type/electroclinical syndrome

\begin{tabular}{|c|c|}
\hline $\begin{array}{l}\text { Seizure type/electroclinical } \\
\text { syndrome }\end{array}$ & $\begin{array}{l}\text { Commonly used first-line } \\
\text { AEDs }\end{array}$ \\
\hline \multicolumn{2}{|l|}{$\begin{array}{l}\text { Generalized genetic or presumed } \\
\text { genetic etiology }\end{array}$} \\
\hline $\begin{array}{l}\text { - Juvenile myoclonic epilepsy, } \\
\text { juvenile absence epilepsy, epilepsy } \\
\text { with generalized tonic clonic } \\
\text { seizures alone }\end{array}$ & $\begin{array}{l}\text { Valproic acid, lamotrigine, } \\
\text { levetiracetam, topiramate, } \\
\text { zonisamide, benzodiazepines }\end{array}$ \\
\hline - Childhood absence epilepsy & $\begin{array}{l}\text { Ethosuximide, valproic acid, } \\
\text { lamotrigine }\end{array}$ \\
\hline $\begin{array}{l}\text { - Genetic epilepsy with febrile } \\
\text { seizures plus }\end{array}$ & $\begin{array}{l}\text { Levetiracetam, lamotrigine, } \\
\text { valproic acid }\end{array}$ \\
\hline \multicolumn{2}{|l|}{$\begin{array}{l}\text { Generalized, structural, or } \\
\text { unknown etiology }\end{array}$} \\
\hline $\begin{array}{l}\text { - Lennox-Gastaut, myoclonic } \\
\text { atonic epilepsy }\end{array}$ & $\begin{array}{l}\text { Valproic acid, lamotrigine, } \\
\text { topiramate, clobazam, rufinamide }\end{array}$ \\
\hline $\begin{array}{l}\text { Focal, structural/metabolic, } \\
\text { or unknown etiology }{ }^{b}\end{array}$ & $\begin{array}{l}\text { Carbamazepine, oxcarbazepine, } \\
\text { levetiracetam, valproic acid }\end{array}$ \\
\hline West syndrome & $\begin{array}{l}\mathrm{ACTH} \text {, high-dose prednisolone, } \\
\text { vigabatrin }\end{array}$ \\
\hline $\begin{array}{l}\text { Epilepsy with continuous } \\
\text { spike-wave in sleep or Landau-Kleffner } \\
\text { Syndrome }^{c}\end{array}$ & $\begin{array}{l}\text { Levetiracetam, high-dose } \\
\text { diazepam, steroids }\end{array}$ \\
\hline Dravet Syndrome & $\begin{array}{l}\text { Valproic acid, benzodiazepines, } \\
\text { topiramate, stiripentol }\end{array}$ \\
\hline
\end{tabular}

Notes: ${ }^{\mathrm{A} A}$ ketogenic diet should be considered early if medication is ineffective; bsurgical therapy should be considered in patients with single presumed focus after two or more AEDs have failed for lack of efficacy; 'no randomized controlled trials; recommendations based on clinical experience only; 'dcompassionate use only in the US.

Abbreviations: AEDs, antiepileptic drugs; ACTH, adrenocorticotropic hormone. 
Dravet syndrome is a malignant epilepsy type presenting in the first 18 months of life with prolonged hemiconvulsive seizures often triggered by hyperthermia. Seizures are intractable, intellectual disability is present, and mortality rate is elevated due to sudden unexplained death in epilepsy, status epilepticus, or accidental injury. Stiripentol, a medication with multiple mechanisms of action including enhancement of inhibitory, $\gamma$-aminobutyric acid (GABA) neurotransmission and inhibition of the cytochrome $\mathrm{p} 450$ (CYP) system, has been shown to have remarkable efficacy, when used in combination with valproic acid and/or clobazam. In a randomized, placebo-controlled trial, Chiron et al showed that $71 \%$ of the stiripentol-treated group, versus only $5 \%$ of the placebo group had a greater than $50 \%$ reduction in generalized tonic-clonic seizures, and $43 \%$ of the stiripentol-treated group was free of this seizure type..$^{18}$ Several other studies have now confirmed this favorable response. ${ }^{19-21}$ This medication is well-tolerated with the most common side effects being drowsiness, ataxia, diplopia, loss of appetite, nausea, and abdominal pain, but it has significant interactions with other medications. Stiripentol is not yet routinely available in the US but can be obtained on compassionate use.

For children with Lennox-Gastaut syndrome, lamotrigine, topiramate, felbamate, rufinamide, and clobazam have been shown to be more efficacious than placebo, although none provided exceptional seizure control. ${ }^{22-26}$

Sulthiame, a carbonic anhydrase inhibitor which is not routinely available in the US, has shown unique efficacy in benign epilepsy of childhood with centrotemporal spikes, both controlling seizures and causing a marked reduction in spike frequency. ${ }^{27}$ Typical cases of this benign syndrome often do not need prophylactic AED treatment. However sulthiame has its bigger role in the atypical cases, where epileptiform discharges are more frequent and may adversely impact intellect, language, and behavior. ${ }^{28-30}$ Side effects include parasthesia, nausea, drowsiness, cognitive impairment, and rarely allergic reactions, particularly in those with sulfa allergies.

For absence epilepsy, several studies have documented equivalent responses for ethosuximide and valproate. ${ }^{31,32}$ A more recent study focussing on newly diagnosed childhood absence epilepsy showed that ethosuximide and valproate were more effective than lamotrigine. ${ }^{33}$

For patients with juvenile myoclonic epilepsy, there is no clear first-choice AED, although clonazepam, lamotrigine, levetiracetam, topiramate, valproate, and zonisamide may all have some efficacy. ${ }^{8}$

In children with progressive myoclonic epilepsies, piracetam, a medication which is not routinely available in the US, has been shown in several studies to be dramatically effective. ${ }^{34,35}$ The optimal dose varies considerably among studies, with some adults receiving up to $45 \mathrm{~g} /$ day. ${ }^{35}$ Side effects are more common at high doses and include dizziness, drowsiness, agitation, nausea, and gastrointestinal discomfort.

For children without defined syndromes, studies comparing carbamazepine, oxcarbazepine, clobazam, lamotrigine, phenytoin, phenobarbital, topiramate, and valproic acid showed equivalent efficacy between these agents, although differences in side-effect frequencies were noted. ${ }^{36-46}$

\section{Exacerbation of specific seizure types or electroclinical syndromes}

Occasionally, AEDs may paradoxically worsen seizures, or lead to the evolution of new seizure types. Carbamazepine has been the medication most commonly implicated. In patients with generalized spike-wave discharge, it may aggravate typical and atypical absences, myoclonus, and atonic seizures, and precipitate nonconvulsive status epilepticus. ${ }^{47,48}$ Worsening of myoclonus can also occur in Angelman syndrome or the progressive myoclonic epilepsies. ${ }^{47,49}$ While carbamazepine is usually effective in the treatment of benign epilepsy of childhood with centrotemporal spikes, it can occasionally exacerbate electrical status epilepticus during sleep or epileptic negative myoclonus, and, as such, should not be used in Landau-Kleffner syndrome. . $^{50,51}$

Phenytoin is contraindicated in progressive myoclonic epilepsy as it results in more rapid disease progression. ${ }^{52}$ It may also aggravate absence or myoclonic seizures in other generalized epilepsies. Phenytoin may also worsen seizures at toxic doses.

Lamotrigine is contraindicated in children with Dravet syndrome, with one study documenting significant seizure exacerbation in $80 \%$ of children with a marked increase in unilateral and convulsive seizures in $40 \% .^{53}$

Other AEDs may also exacerbate certain seizure types, including absence and myoclonic seizures with vigabatrin and absence seizures with tiagabine. Although benzodiazepines are commonly utilized in children with Lennox-Gastaut syndrome, intravenous benzodiazepines given to treat nonconvulsive status epilepticus can occasionally provoke tonic seizures. ${ }^{54}$

\section{Tolerability}

Given that many medications appear to have similar effectiveness, choice of first-line AEDs in children with epilepsy is often influenced by side-effect profile, other 
preexisting conditions, need for blood monitoring, ease of administration, experience in a pediatric population, and cost. Approximately $30 \%$ of children continue to have seizures following their first medication and additional medications are often added. Children on polytherapy are at greater risk of side effects, and medications should be withdrawn if they are ineffective.

\section{Side effects of AEDs}

All medications have the potential for adverse side effects. In general, side effects are felt to be more problematic with first-generation AEDs (phenytoin, phenobarbital, carbamazepine, and valproic acid) than with many of the newer second generation agents. Specific adverse effects are more commonly seen with certain medications or classes of medication. Alternatively, there may be certain attributes of a given child that make them more susceptible to specific types of side effects.

Side effects of AEDs can be subdivided into those which are common (which may be bothersome but are usually not life-threatening) and those which are rare (which can be serious and/or life-threatening).

\section{Common, pharmacology-related side effects}

Common side effects are predominantly pharmacology related, meaning they are predictable, dose dependent, and explained by the known pharmacologic properties of each medication. These side effects are generally reversible with dosage reduction or medicine discontinuation. Classes of medications and side effects with which they are most commonly associated are listed in Table 2.

Approximately one quarter of children with epilepsy have a degree of intellectual disability, and many more have specific learning problems. ${ }^{55}$ Overall, newer antiepileptic agents (with the exception of topiramate and zonisamide) are believed to have fewer cognitive effects than older AEDs. ${ }^{56}$ Regarding the older agents, adverse cognitive effects are most common with phenobarbital and benzodiazepines, whereas the cognitive profiles of valproate, carbamazepine, and phenytoin are comparable, but less problematic. Lamotrigine or oxcarbazepine are considered "cleaner" medications with more limited potential to adversely impact learning.

Attention deficit disorder affects up to one third of children with epilepsy, and its prevalence is even higher amongst children with medically intractable epilepsy. ${ }^{57,58}$ Medications such as benzodiazepines, phenobarbital, levetiracetam, and valproic acid tend to exacerbate such symptoms.
Table 2 Common adverse effects of antiepileptic medications

\begin{tabular}{|c|c|}
\hline Adverse effect & $\begin{array}{l}\text { Class/type of antiepileptic drug most } \\
\text { commonly implicated }\end{array}$ \\
\hline \multicolumn{2}{|l|}{ Neurocognitive } \\
\hline $\begin{array}{l}\text { - Sedation, fatigue, } \\
\text { sleepiness }\end{array}$ & $\begin{array}{l}\text { All, but more commonly benzodiazepines, } \\
\text { phenobarbital, topiramate, zonisamide, } \\
\text { felbamate, rufinamide, pregabalin, tiagabine }\end{array}$ \\
\hline $\begin{array}{l}\text { - Ataxia, vertigo, } \\
\text { diplopia }\end{array}$ & $\begin{array}{l}\text { Carbamazepine, oxcarbazepine, phenytoin, } \\
\text { lacosamide }\end{array}$ \\
\hline - Tremor & $\begin{array}{l}\text { Valproic acid, carbamazepine, oxcarbazepine, } \\
\text { phenytoin }\end{array}$ \\
\hline $\begin{array}{l}\text { - Slow thinking, } \\
\text { word-finding problems }\end{array}$ & $\begin{array}{l}\text { Topiramate, zonisamide, phenobarbital, } \\
\text { benzodiazepines }\end{array}$ \\
\hline - Insomnia & Felbamate, vigabatrin, levetiracetam \\
\hline $\begin{array}{l}\text { - Hyperactivity, } \\
\text { inattention }\end{array}$ & $\begin{array}{l}\text { Benzodiazepines, phenobarbital, levetiracetam, } \\
\text { valproic acid }\end{array}$ \\
\hline $\begin{array}{l}\text { - Irritability, behavioral } \\
\text { problems }\end{array}$ & $\begin{array}{l}\text { Benzodiazepines, phenobarbital, } \\
\text { levetiracetam, vigabatrin }\end{array}$ \\
\hline $\begin{array}{l}\text { - Mood changes, } \\
\text { depression }\end{array}$ & $\begin{array}{l}\text { Levetiracetam, phenobarbital, } \\
\text { benzodiazepines, vigabatrin, topiramate, } \\
\text { zonisamide }\end{array}$ \\
\hline \multicolumn{2}{|l|}{ Gastrointestinal } \\
\hline - Nausea, vomiting & $\begin{array}{l}\text { Felbamate, valproic acid, ethosuximide, } \\
\text { oxcarbazepine, carbamazepine, lamotrigine, } \\
\text { topiramate, zonisamide, rufinamide }\end{array}$ \\
\hline - Anorexia & Topiramate, zonisamide, felbamate \\
\hline - Increased appetite & Valproic acid, clobazam, pregabalin \\
\hline Headache & $\begin{array}{l}\text { Rufinamide, levetiracetam, lamotrigine, } \\
\text { oxcarbazepine, lacosamide }\end{array}$ \\
\hline \multicolumn{2}{|l|}{ Electrolyte disturbances } \\
\hline - Hyponatremia & Oxcarbazepine, carbamazepine \\
\hline - Metabolic acidosis & Topiramate, zonisamide \\
\hline \multicolumn{2}{|l|}{ Bone } \\
\hline $\begin{array}{l}\text { - Reduced bone } \\
\text { mineral density }\end{array}$ & $\begin{array}{l}\text { Phenobarbital, primidone, phenytoin, } \\
\text { carbamazepine, valproate, oxcarbazepine }\end{array}$ \\
\hline
\end{tabular}

Although studies are limited, anxiety and depression may affect up to one quarter of children with epilepsy. While depression and suicidal ideation may be exacerbated by any antiepileptic medication, this risk may be higher with levetiracetam and GABAergic medications such as vigabatrin, phenobarbital, benzodiazepines, or topiramate. ${ }^{59}$

Although cognitive and neuropsychiatric comorbidities are frequent in children with epilepsy, they are often undiagnosed and/or untreated. While AEDs may exacerbate these symptoms, it is important to correctly diagnose these entities and initiate appropriate therapy, if needed. Children who develop similar neurocognitive adverse effects to several medications are likely to have an undiagnosed comorbidity, and need further evaluation. In children predisposed to neurobehavioral side effects, including those with intellectual disability and preexisting behavior problems, starting at lower doses, and employing slower titrations may minimize these effects. 
Many AEDs are associated with reduced bone mineral density and increased risk of osteoporosis and fractures. Increased bone turnover is one of the major factors. AEDs most commonly associated with reduced bone mineral density include the inducers of the CYP system (phenobarbital, primidone, phenytoin, and carbamazepine), oxcarbazepine, and valproate. Vitamin D supplementation (usual dose 400-1000 IU/day) should be routinely prescribed in children on these AEDs. ${ }^{60}$

\section{Serious, idiosyncratic side effects}

Serious adverse effects are rare but may be life-threatening, and are listed in Table 3. These are more commonly idiosyncratic, meaning their pathogenesis is unrelated to the known mechanism of action of the drug, and they may not be reversible with medication discontinuation. While idiosyncratic side effects are relatively unpredictable, some are more of a concern at specific ages, in specific ethnic groups, or with other associated conditions or medications.

There is remarkably little data about the effects of AEDs on the developing brain. Studies in rat pups have suggested that phenytoin, phenobarbital, diazepam, clonazepam,

Table 3 Rare, serious adverse effects of antiepileptic medications

\begin{tabular}{|c|c|}
\hline Adverse effect & Antiepileptic drug \\
\hline \multicolumn{2}{|l|}{ 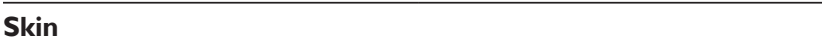 } \\
\hline $\begin{array}{l}\text { - Allergic rash/ } \\
\text { Stevens-Johnson syndrome }\end{array}$ & $\begin{array}{l}\text { Lamotrigine, phenytoin, } \\
\text { phenobarbital, carbamazepine, } \\
\text { oxcarbazepine, rufinamide }\end{array}$ \\
\hline \multicolumn{2}{|l|}{ Gastrointestinal } \\
\hline - Hepatic failure & Valproic acid, felbamate \\
\hline - Pancreatitis & Valproic acid \\
\hline \multicolumn{2}{|l|}{ Bone marrow } \\
\hline - Aplastic anemia & $\begin{array}{l}\text { Felbamate, carbamazepine, } \\
\text { phenytoin, phenobarbital, } \\
\text { ethosuximide }\end{array}$ \\
\hline \multicolumn{2}{|l|}{ Cardiac } \\
\hline - Arrhythmias & $\begin{array}{l}\text { Rufinamide - shortened QT interval } \\
\text { Lacosamide - prolonged PR interval }\end{array}$ \\
\hline \multicolumn{2}{|l|}{ Kidney } \\
\hline - Nephrolithiasis & Topiramate, zonisamide \\
\hline \multicolumn{2}{|l|}{ Eye } \\
\hline - Irreversible peripheral field loss & Vigabatrin \\
\hline - Angle closure glaucoma & Topiramate \\
\hline \multicolumn{2}{|l|}{ Psychiatric } \\
\hline - Suicide & Blackbox warning for all AEDs \\
\hline \multicolumn{2}{|l|}{ Metabolic } \\
\hline $\begin{array}{l}\text { - Worsening of rare inborn } \\
\text { disorders of metabolism }\end{array}$ & Valproic acid \\
\hline \multicolumn{2}{|l|}{ Reproductive $^{a}$} \\
\hline - Polycystic ovarian syndrome & Valproic acid \\
\hline - Teratogenicity (highest risk) & Valproic acid, phenytoin \\
\hline
\end{tabular}

Note: ${ }^{\text {AAll }}$ AEDs have a potential risk of teratogenicity.

Abbreviation: AEDs, antiepileptic drugs. vigabatrin, valproate and sulthiame, but not levetiracetam or topiramate cause apoptotic neurodegeneration at plasma concentrations relevant for seizure control in humans. ${ }^{61-63}$ While these results are concerning, it is not clear if this effect is also noted when these medications are used in human neonates.

Valproic acid is associated with transient elevations in liver function tests in approximately $15 \%-30 \%$ and in rare cases may cause fatal hepatotoxicity, with pathological findings of microvesicular steatosis and necrosis of hepatocytes. The risk of fatal hepatotoxicity is greatest in children less than 2 years' old on polytherapy, ${ }^{64-67}$ with an estimated risk of approximately 1 per $500-800 .{ }^{65}$ Several possible pathogenic mechanisms for fatal hepatotoxicity have been proposed, including underlying inborn errors of metabolism (particularly mitochondrial disease) ${ }^{68}$ inhibition of beta-oxidation by valproate, ${ }^{69}$ and toxicity from unsaturated metabolites of valproate, namely 4-ene-VPA and 2,4diene-VPA. ${ }^{70}$ Shen et al showed that infants and young children treated with valproate have higher 4-ene-VPA/VPA ratios, thus placing them at greater risk of this serious side effect. ${ }^{71}$ Furthermore, concurrent therapy with enzyme inducers such as phenytoin, carbamazepine, and stiripentol result in increased 4-ene-VPA, the presumed hepatotoxic metabolite. ${ }^{72}$ Cases of fatal hepatoxicity resulting from valproate therapy in children with undiagnosed Alpers disease, ${ }^{73,74}$ and medium acyl-coenzyme A dehydrogenase ${ }^{75}$ have been reported. Valproate may also result in metabolic decompensation in other metabolic disorders such as nonketotic hyperglycinemia and urea cycle defects. ${ }^{76}$ Routine metabolic screening, particularly in children with symptoms suggestive of a possible underlying metabolic disorder should be carried out prior to initiation of valproic acid therapy. Because valproate-induced hyperammonemia and hepatotoxicity may be mediated in part by carnitine deficiency, some committees and textbooks have recommended carnitine supplementation during valproate therapy in high risk children. ${ }^{77}$ Carnitine supplementation does not appear harmful, and this practice seems reasonable in high-risk children, despite the lack of clear data to support the practice. Pancreatitis is also a rare and potentially fatal complication with valproic acid therapy.

The risk of allergic reaction and possible StevensJohnson syndrome is common to many AEDs. Genetics plays a significant role in these reactions. Anticonvulsant hypersensitivity syndrome is relatively uncommon, affecting up to 1/1000 individuals, and presenting with rash, fever, lymphadenopathy, and multiorgan involvement. It is 
predominantly seen with arene oxide-producing AEDs such as phenytoin, carbamazepine, phenobarbital, and primidone. If children react to one drug in this category, they have up to a $70 \%$ risk of having similar reactions to another and also have a higher risk of reaction with lamotrigine and oxcarbazepine. Furthermore, their siblings have a $25 \%$ chance of a similar reaction if exposed to these agents. ${ }^{78}$ Several studies have now reported specific polymorphisms to be associated with a higher risk of idiosyncratic reactions to specific AEDs, the most important being the association of HLA B*1502 with reaction to carbamazepine in the Han Chinese population. ${ }^{79}$ It is likely that with further advances in this area, specific pharmacogenomic testing will be helpful in identifying children at highest risk of this complication.

Skin rash with lamotrigine presents as a maculopapular or morbilliform eruption, which is usually seen within 2-6 weeks of therapy initiation, and which may progress to Stevens-Johnson syndrome. The biggest risk factor for rash is rapidity of titration. Other risk factors include young age and concurrent valproic acid, and to a lesser degree enzyme-inducing AEDs. Lamotrigine is metabolized through two pathways: (1) metabolism by a uridine diphosphate glucuronosyltransferase (UGT) enzyme to lamotrigineglucuronide, and (2) metabolism by the CYP system to a reactive arene-oxide intermediate, and lamotrigineinduced rash is thought to be related to formation of the latter. Concurrent valproate therapy blocks conversion of lamotrigine to lamotrigine-glucuronide, and hence increases the formation of the arene-oxide intermediate. ${ }^{80}$ The enzyme inducers (carbamazepine, phenytoin, and phenobarbital) induce CYP, which results in preferential metabolism to the arene-oxide metabolite. Children are at increased risk of lamotrigine-induced skin rash because their CYP metabolism is increased, again resulting in enhanced formation of the arene-oxide reactive metabolite.

Felbamate is a highly efficacious medication. Its use is limited at present to children with epilepsy refractory to multiple other AEDs. It has two serious, idiosyncratic reactions, aplastic anemia and hepatotoxicity, both of which became apparent only after it was marketed in 1993. A total of 34 cases of aplastic anemia have been described, 13 of which have been fatal. ${ }^{81}$ Based on the number of exposed patients at the time of this report, the estimated risk for aplastic anemia with felbamate use is approximately 1 in 4000-5000. However, the risk is likely much lower in children, as aplastic anemia has not been described under the age of 13 years, and predominantly affects white, middleaged females. Factors associated with greater risk of aplastic anemia include prior history of AED allergy, history of prior cytopenia, and underlying immune disorder. It was seen at a mean of 173 days after initiation of felbamate. Eighteen cases of hepatic failure have been reported; however, after careful review, only seven were felt to have a "likely association" with felbamate, ${ }^{81}$ two of which were under 17 years of age. Based on numbers of patients exposed to felbamate, the estimated risk of fatal hepatotoxicity is approximately one per 18,500-25,000 exposures. These seven cases presented at a range of 25-181 days after felbamate initiation. The mechanism of felbamate-induced toxicities is unknown; however, it has been proposed that 2-phenylpropenal, a reactive metabolite of felbamate and a very potent immunogen, may be responsible. ${ }^{82}$

Vigabatrin has two important risks which must be considered prior to initiation of therapy, namely peripheral vision loss and $\mathrm{T} 2$ hyperintensities on magnetic resonance imaging. The prevalence of visual field deficits depends on duration and dose of therapy, usually appearing only after months of treatment. It is seen in approximately $15 \%$ of children and between $15 \%-31 \%$ of infants. ${ }^{83}$ Detection of field deficits in infants is challenging and an electroretinogram looking specifically at the $30 \mathrm{~Hz}$ flicker amplitude or the cone B wave amplitude may be helpful. Limiting the duration of therapy to no longer than 6 months will minimize the risk of permanent field deficits. Taurine supplementation may reduce the risk of peripheral vision loss but needs further study in humans. In rats, taurine supplementation was shown to reverse retinal lesions and, in particular, retinal ganglion cell loss caused by vigabatrin. ${ }^{84}$ Vigabatrin therapy has also been associated with transient, asymptomatic magnetic resonance imaging signal changes and reversible diffusion restriction in the deep gray nuclei and brainstem in up to one third of infants. ${ }^{83,85}$ The majority of these changes resolve, even in those in whom vigabatrin therapy is continued.

Hematological idiosyncratic reactions including aplastic anemia and agranulocytosis are seen with many AEDs including felbamate. A case-control study in the UK found that AEDs, particularly carbamazepine and valproic acid, were associated with a ninefold increase of aplastic anemia. ${ }^{86}$

\section{Monitoring for side effects}

Patients and their families should be counseled on both common and rare serious adverse effects prior to initiation of medications. Common, pharmacologically related side effects often respond to lowering the dose or slowing the titration rate. Routine laboratory testing including complete blood count and liver function studies is advised prior to 
AED initiation, to detect any preexisting concerns. While blood monitoring is frequently performed periodically in children on AEDs, the effectiveness of this practice remains unproven. In a prospective study of 199 children with epilepsy on AEDs, Camfield et al reported that routine screening of asymptomatic children was not indicated, and might actually interfere with treatment. ${ }^{87}$ Furthermore, this practice may lead to false security. Most idiosyncratic reactions present very acutely, over hours to days, meaning that even if blood work is obtained on a monthly or bi-monthly basis, it would be unlikely to result in earlier detection of these reactions. For most children, careful education of families regarding the early signs and symptoms of idiosyncratic reactions, and testing at the time of presentation of these symptoms is a more reasonable approach. Additionally, minor reductions in white blood cell counts are not uncommon with viral infections in otherwise asymptomatic children, but could lead to discontinuation of an effective AED because of fear of aplastic anemia or agranulocytosis. Similarly, transient minor increases in liver enzymes may be seen with viral infections, and are not uncommonly seen in children on AEDs, who remain asymptomatic.

\section{Ease of use}

Many medications have specific "child-friendly" formulations marketed, including suspensions and chew or dispersible tablets. Frequency of dosing should also be considered, as compliance decreases if medication must be given more often than twice daily. While long-acting or sustained-release preparations are marketed for several AEDs, the more rapid gastrointestinal motility in young children may reduce their effectiveness.

\section{Pharmacokinetics}

Pharmacokinetics in the pediatric population is constantly shifting during development, affecting absorption, bioavailability, metabolism, and excretion (Table 4). As antiepileptic drugs typically have a relatively narrow therapeutic window, these age-related changes mandate that special care be taken in the use of these medications in the pediatric population.

\section{Differences in cerebral maturation}

Changes in the neurobiology of the developing brain alter seizure susceptibility during childhood, with increased neuronal excitability during the neonatal period. Between $2 \%$ and $4 \%$ of children will have a convulsion before age 5 and the highest incidence of epilepsy is during the first year of life. ${ }^{88}$ There are a myriad of reasons for this - genetic, metabolic, and traumatic occurrences associated with early life, but there exist fundamental physiological alterations in the immature brain that may lead to differences in epileptogenicity.

Repeated studies have shown that GABA has a paradoxical effect in neonatal neurons and is excitatory rather than inhibitory. Immature neurons contain a reversed chloride gradient, with a higher concentration inside the neuron, which is opposite compared to mature neurons. As a result, the activation of GABA receptors results in outward flow of chloride and resultant depolarization of the neuron. ${ }^{89}$ This is due to increased expression of NKCC1 transporter channels in the immature neuron, which allow for the influx of chloride into neurons. As the neuron matures, there is increased expression of KCC2 channels, which remove chloride from the neuron..$^{90}$ These findings suggest that it could be possible to better target neonatal seizures. The diuretic bumetanide specifically blocks NKCC1 and may be potentially useful in treating neonatal seizures. ${ }^{91}$ Its efficacy is currently being tested in clinical trials.

Seizure cessation differs in immature brains. In adults, the substantial nigra pars reticulata is thought to play a role in the cessation of seizures, due to its high concentration of GABAergic neurons. This may not hold true in the developing brain. Activation of the $\mathrm{GABA}_{\mathrm{A}}$ receptors in the substantia nigra has been shown to exert a proconvulsant effect in immature male rats. It has been postulated that this may be an effect of developing sex hormones, which change during development. ${ }^{92}$ These data highlight important

Table 4 Pharmacokinetics by age

\begin{tabular}{|c|c|c|c|c|c|}
\hline & & $\begin{array}{l}\text { Neonate } \\
\text { (0-3 months) }\end{array}$ & $\begin{array}{l}\text { Infant } \\
\text { (3-12 months) }\end{array}$ & $\begin{array}{l}\text { Toddler } \\
\text { (I-3 years) }\end{array}$ & $\begin{array}{l}\text { Child } \\
\text { (3-18 years) }\end{array}$ \\
\hline \multicolumn{2}{|c|}{ Gastric absorption } & $\downarrow$ & $\downarrow$ & $\downarrow$ & $\leftrightarrow$ \\
\hline \multicolumn{2}{|c|}{ Protein binding } & $\downarrow$ & $\downarrow$ & $\leftrightarrow$ & $\leftrightarrow$ \\
\hline Hepatic & CYP & $\downarrow$ & $\uparrow$ & $\uparrow$ & $\uparrow$ \\
\hline metabolism & UGT & $\downarrow$ & $\downarrow$ & $\downarrow / \uparrow$ & $\uparrow$ \\
\hline Renal cleara & & $\downarrow$ & $\downarrow$ & $\downarrow / \leftrightarrow$ & $\leftrightarrow$ \\
\hline
\end{tabular}

Abbreviations: CYP, cytochrome p450; UGT, uridine diphosphate glucuronosyltransferase. 
changes the brain undergoes during maturation - affecting both seizure onset and cessation.

Separate from seizure generation and propagation, the immature brain presents a unique challenge in drug delivery to the central nervous system. The integrity of the blood-brain barrier is maintained by tight junctions between endothelial cells in the blood vessels and choroid plexus and in the meninges. These tight junctions limit the passage of compounds in either direction and are a barrier to the penetration of antiepileptic drugs into the central nervous system. Early animal studies suggested that there was a less well developed blood-brain barrier in immature animals, but human ultrastructural studies have now shown that the neonatal tight junctions in the blood-brain barrier have a similar appearance to adult junctions. These data suggest that a mature blood-brain barrier is in place early in development. ${ }^{93}$

\section{Differences in absorption}

Drug absorption is dependent upon gastric $\mathrm{pH}$, gastric contents, gastric emptying time, and gastrointestinal motility. All of these variables change through early development, affecting the absorption of medications in children. During the neonatal period, the gastric contents are nearly neutral and it is not until age 2 years that the $\mathrm{pH}$ reaches that of an adult. ${ }^{94}$ Thus, antiepileptic medications with a weakly acidic composition, such as phenytoin and phenobarbital, may have decreased absorption due to the weakly acidic stomach in a young child. This population subsequently requires higher dosing to achieve a therapeutic level. ${ }^{95}$ Premature infants may have an even longer delay in maturation of acidic production. ${ }^{96}$ In addition to $\mathrm{pH}$, gastrointestinal motility in infants varies from adults. There is prolonged gastric emptying time and irregular peristalsis, further affecting absorption of medications. ${ }^{94}$ These differences, which are particularly pronounced in premature infants, lead to delayed gastric absorption and higher time to peak serum levels. ${ }^{96}$

Additionally, developmental changes in the gastrointestinal production of pancreatic enzymes and biliary fluid affect the ability of the gastrointestinal tract to absorb medications. ${ }^{96}$ Uptake may further be affected by active efflux transporters, which have been shown to be crucial for the uptake of medications that do not undergo extensive biotransformation. While this effect has not been shown with antiepileptic drugs specifically, the demonstration of differences in uptake with other drugs such as fexofenadine suggests that this phenomenon may be transferable to other types of medications. ${ }^{97}$ Though there is evidence that these transporters are mature by
6 months of age, their function in early infancy is unknown. Data are lacking on how these transporters affect the uptake of different antiepileptic medications. ${ }^{95}$

\section{Differences in drug distribution}

Multiple shifting targets, including body fat percentage, volume of distribution, and protein binding affect drug distribution in the pediatric population. Neonates and infants have an increased body water:body fat ratio compared to adults, resulting in an increase in the volume of distribution for hydrophilic drugs, including phenobarbital. Due to this increased ratio, a higher dose is required to achieve therapeutic levels. Lipophilic compounds are not significantly affected by the amount of body fat. ${ }^{95}$

Protein binding affects the bioavailability of medications. The production of albumin and $\alpha 1$-acid-glycoprotein is decreased during the first year of life. For medications that are highly protein bound, particularly phenytoin and valproic acid, the unbound/total plasma concentrations are increased compared to adults. The total serum levels are then unreliable and free levels are required to ensure that serum levels are within the appropriate therapeutic window. ${ }^{98}$

\section{Differences in metabolism and excretion (Table 5)}

The majority of antiepileptic drugs rely, to some extent, on hepatic metabolism and clearance. Constantly shifting activity levels of various hepatic enzymes during childhood leads to variable hepatic metabolism of antiepileptic drugs. The most commonly involved pathways for hepatic metabolism are the CYP and UGT systems. Though multiple factors, including genetic and environmental, can affect these systems, agedependent maturation plays a role in all children.

The most active enzyme is CYP3A4. Activity is negligible at birth, reaches $20 \%$ of adult levels at 1 month, and $72 \%$ at 1 year. Conversely, activity is increased compared to adults in childhood, maximally from the age of 2 to 12 years, and then steadily decreasing to adult activity levels from the age of 12 to 16 years. ${ }^{95}$ As a result, for medications metabolized by CYP3A4, specifically carbamazepine, ethosuximide, and midazolam, infants require a lower dose, while children must have a higher weight-based dose compared to adults. Due to increased metabolism, children may also require more frequent dosing in order to maintain steady drug levels.

Though most CYP enzymes have increased activity during childhood, CYP2C19 is the exception, with similar activity levels in children and adults. This enzyme is involved in the metabolism of phenytoin and diazepam. ${ }^{98}$ The UGT system 
Table 5 Pathways for the metabolism and excretion of antiepileptic medications

\begin{tabular}{ll}
\hline Primary pathway of metabolism and excretion & \\
Renal & Gabapentin \\
& Pregabalin \\
Vigabatrin \\
Hepatic - CYP & Carbamazepine \\
& Clobazam \\
& Phenytoin \\
Hepatic - UGT & Midazolam \\
Hepatic - CYP and UGT & Lamotrigine \\
& Lorazepam \\
Hepatic - Non CYP or UGT & Tiagabine \\
Combined renal and hepatic & Valproic acid \\
& Rufinamide \\
& Ethosuximide \\
& Felbamate \\
& Lacosamide \\
& Levetiracetam \\
& Oxcarbazepine \\
& Phenobarbital \\
& Topiramate \\
& Zonisamide \\
\hline
\end{tabular}

Abbreviations: CYP, cytochrome p450; UGT, uridine diphosphate glucuronosyltransferase.

is involved in the metabolism of lamotrigine and lorazepam. UGT activity is minimal at birth and reaches adult levels of activity between 2 and 4 years of age. During childhood, the activity level is slightly increased compared to adult levels but, overall, less of a difference is seen compared to CYP enzymes. As a result, drugs metabolized by this system require a higher dose during infancy and early childhood, but can be given in adult-equivalent doses during later childhood.

For antiepileptic medications metabolized by multiple pathways, it is more difficult to predict age-appropriate doses. Valproic acid and tiagabine undergo metabolism by both the CYP and UGT systems. Clobazam and clonazepam are also metabolized by multiple pathways. ${ }^{98}$

Glomerular filtration in infants is only $25 \%-30 \%$ that of adults. At 6 months of age, it increases to $50 \%-75 \%$ of adult levels and is not mature until the age of 2 or 3 years. ${ }^{99}$ Tubular secretion lags behind glomerular filtration. It is unknown at what point the production of proteins crucial for renal excretion and re-absorption of molecules is fully matured. For antiepileptic medications that are largely excreted through the kidneys, such as gabapentin and vigabatrin, this could subsequently lead to increased serum levels. ${ }^{95}$

Multiple widely used antiepileptic medications undergo combined hepatic metabolism and renal excretion. Ethosuximide, felbamate, levetiracetam, oxcarbazepine, phenobarbital, topiramate, and zonisamide are all eliminated by a combination of hepatic and renal pathways. This variability requires separate considerations for total daily doses and dosing frequency for each medication. ${ }^{98}$

\section{Role of monitoring serum levels}

Antiepileptic medications mostly have a narrow therapeutic window, in which too low a dose may prove ineffective and too high a dose carries a risk of adverse effects. Serum medication levels assist in gauging where within the therapeutic window a patient may fall. However, while therapeutic ranges have been well established in older antiepileptics such as phenytoin, carbamazepine, and valproate, the desired serum concentration for many newer AEDs is less well defined. The necessary frequency of serum monitoring also lacks clear definition.

Phenytoin, carbamazepine, phenobarbital, and valproic acid are all widely used older AEDs with narrow therapeutic ranges. Serum levels are well correlated with clinical efficacy and elevated levels are consistently associated with toxicity. When variables such as protein binding, metabolism, and drug interactions are factored in, serum levels of these medications may provide a reasonable guideline for dosing. However, even with these medications, serum levels are not absolute measures of efficacy or toxicity. In a study of adult patients on phenobarbital or phenytoin, well-controlled epilepsy patients with stable "subtherapeutic" serum levels did no worse than those patients with dose adjustments made based upon levels. ${ }^{100}$ Children are different from adults, though, and changing pharmacokinetics could lead to fluctuations with clinical implications.

Newer AEDs, such as levetiracetam, lamotrigine, and topiramate, have less well defined recommended serum levels. In many centers, these tests are performed in outside laboratories and may take several days or weeks to get results. In children, obtaining levels of these new medications can be reasonable in a few situations (Table 6). A serum level after achieving steady state at the initial goal dose can help gauge how rapidly a child is absorbing and metabolizing the new drug. Levels in the setting of complex pharmacotherapy help to judge the effect of drug interactions. Since renal clearance and hepatic metabolism change during early life, periodically testing drug levels may be reasonable to ensure that dosing is keeping up with a child's development. Finally, drug levels are of assistance in assuring compliance with a medication. ${ }^{101}$

\section{Drug interactions}

Although children with epilepsy are less likely than their adult counterparts to be taking multiple medications, clinicians 
Table 6 Indications for checking serum drug levels of antiepileptic medications

Indications for checking serum drug levels

To assess serum concentration at steady state of target dosing

In the setting of complex pharmacokinetics

To assess at various stages of development

To assure compliance

caring for pediatric patients still need to be aware of drug interactions. This is particularly true for the minority of children with epilepsy who do not respond to their first AED and require polytherapy. ${ }^{102}$ Drug interactions typically affect one of three processes: biotransformation (or metabolism), pharmacokinetics (including absorption and protein binding), and pharmacodynamics (including antagonism or synergism between two medications unrelated to serum levels). Utilizing knowledge about drug interactions, the astute clinician can minimize adverse effects, potentially improve seizure control, and help his/her pediatric patients achieve higher quality of life.

\section{Biotransformation}

When exploring interactions between AEDs and other medications, it is critical to explore CYP enzymes. These enzymes, which are predominantly found in the liver, are responsible for the breakdown of multiple AEDs, including carbamazepine, felbamate, phenobarbital, phenytoin, primidone, tiagabine, topiramate, and zonisamide. ${ }^{103} \mathrm{CYP}$ enzymes can be either induced or inhibited by many of the widely utilized AEDs. This is particularly true for three CYP enzymes: CYP2C9, CYP2C19, and CYP3A4. ${ }^{103-105}$ Certain populations are more likely to have mutations for these enzymes (Caucasians for CYP2C9, Japanese for CYP2C19) that promote toxicity, further complicating treatment decisions. ${ }^{106,107}$

Carbamazepine, phenobarbital, phenytoin, and primidone are the AEDs most likely to induce CYP enzymes. ${ }^{103,104}$ This can result in clinically significant reductions in other AEDs (particularly lamotrigine, tiagabine, topiramate, and valproic acid), thereby increasing the risk of breakthrough seizures. ${ }^{103,108}$ If such combinations have previously been prescribed and the clinician wishes to taper the enzymeinducing AED, care must be taken. Often, the dose of the non-enzyme inducing AED will need to be reduced to avoid subsequent toxicity. ${ }^{103,109,110}$ Conversely, valproic acid is known to inhibit CYP enzymes. ${ }^{103,104}$ This can result in increased serum concentrations of certain AEDs (particularly carbamazepine-epoxide, lamotrigine, phenobarbital, and phenytoin), putting patients at higher risk for adverse events. ${ }^{103}$ This can be particularly problematic in children, whose drug levels (particularly lamotrigine) can show wide interindividual variability. ${ }^{111}$ For children with refractory seizures who are already on an enzyme-inducing or -inhibiting AEDs, it may be safer to prescribe a second AED without CYP interactions. These include gabapentin, pregabalin, levetiracetam, and vigabatrin, all of which undergo renal elimination. ${ }^{112}$ Common interactions between AEDs are listed in Table 7.

Although encountered less frequently than in adults, interactions between AEDs and other medications are observed in children. For example, antacids can reduce the absorption of carbamazepine, gabapentin, phenobarbital, and phenytoin by increasing the gastric $\mathrm{pH} .{ }^{113}$ Certain antacids, including omeprazole and cimetidine, can inhibit phenytoin metabolism, increasing the risk of toxicity. ${ }^{114,115}$ Tricyclic antidepressants can inhibit the metabolism of carbamazepine, phenobarbital, and phenytoin, while themselves experiencing an increase in metabolism via induction of CYP enzymes. ${ }^{116}$ Fluoxetine can inhibit CYP enzymes and potentially put children at risk for carbamazepine and phenytoin toxicity. ${ }^{117,118}$ Sertraline, via its inhibition of uridine $5^{\prime}$-diphospho-glucuronosyltransferase, can inhibit the glucuronidation of lamotrigine, resulting in supratherapeutic lamotrigine levels. ${ }^{119}$ Antifungal agents and antibiotics can also interact with AEDs via inhibition of CYP enzymes. Fluconazole has been reported to increase serum levels of phenytoin, while macrolide antibiotics such as erythromycin and clarithromycin can increase serum levels of carbamazepine. ${ }^{120-122}$ Even herbal remedies such as St John's wort may inhibit CYP enzymes enough to result in clinically significant increases in the levels of carbamazepine and phenytoin. ${ }^{123}$ When applicable, children on enzyme-inducing AEDs must be monitored for decreased effectiveness of other medications, including anticancer agents, antiretroviral drugs, corticosteroids, griseofulvin, haloperidol, theophylline, and warfarin. ${ }^{103}$

Special attention to AED choice needs to be exercised when caring for adolescent females on oral contraceptives. There are several AEDs, including carbamazepine, felbamate, oxcarbazepine, phenobarbital, phenytoin, primidone, and topiramate, which can increase the metabolism of oral contraceptives, ${ }^{103,124}$ resulting in unplanned pregnancy. This can be problematic given the risk of AEDs (particularly older AEDs) to cause fetal malformations. ${ }^{125}$ This is especially true when adolescent girls are not receiving regular prenatal care and supplementation with high-dose folate. Conversely, serum levels of lamotrigine are reduced by concurrent oral 


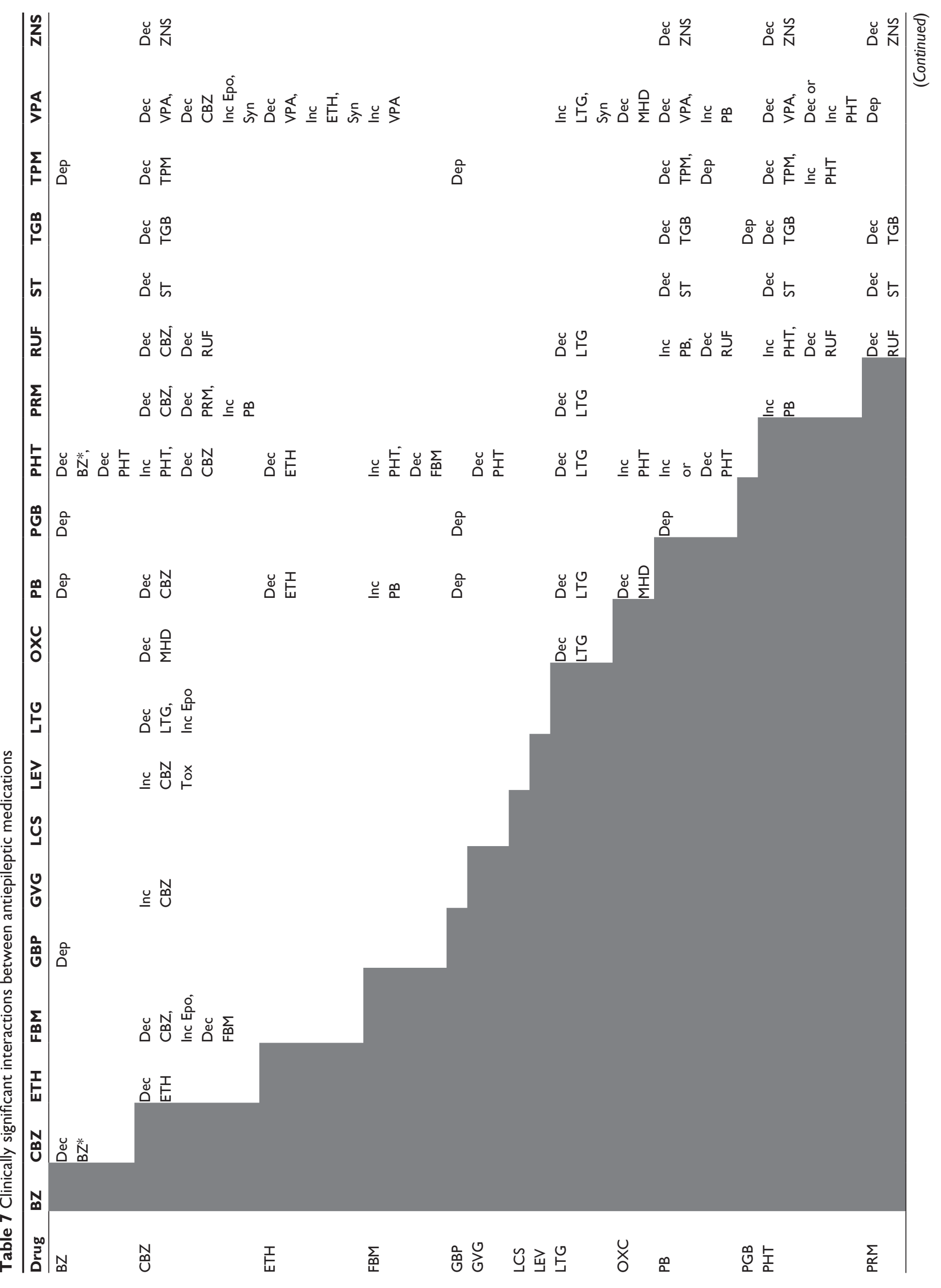




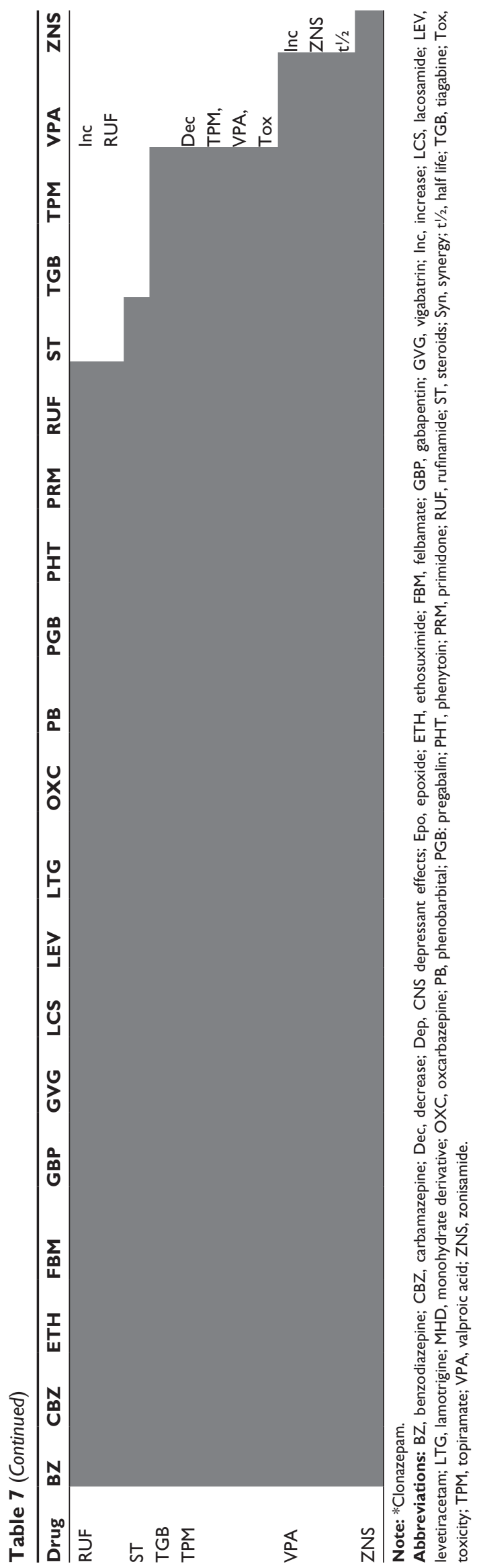

contraceptive use, putting patients at risk for breakthrough seizures. ${ }^{124}$ Although higher doses of lamotrigine can be utilized in such a situation to provide improved seizure coverage, care must be taken to avoid toxicity. If oral contraceptives are discontinued, supratherapeutic lamotrigine levels may result unless the dose is preemptively lowered.

\section{Pharmacokinetics}

Another aspect of drug toxicity/interactions that must be considered when prescribing AEDs to children is pharmacokinetics. Most AEDs have linear pharmacokinetics; when doses are increased or decreased, their serum concentrations change in direct proportion to the increase/ decrease. However, there are five AEDs with nonlinear pharmacokinetics: carbamazepine, phenytoin, valproic acid, gabapentin, and zonisamide. Carbamazepine can induce its own metabolism (autoinduction) via CYP3A4, resulting in reduced serum levels and breakthrough seizures while on stable doses. ${ }^{126}$ Phenytoin and zonisamide owe their nonlinear kinetics to saturation of metabolism, while gabapentin owes its kinetics to saturation of gastrointestinal absorption. ${ }^{103}$ Saturation of plasma protein binding is responsible for the nonlinear kinetics of valproic acid. ${ }^{103,127}$

Phenytoin and valproic acid are unique amongst AEDs for their excess plasma protein binding. Unlike most AEDs, these two medications have clinically relevant $90 \%$ plasma protein binding. Only tiagabine and diazepam have higher protein binding percentages (98\% each). ${ }^{103}$ Any additional medications which are protein bound have the potential to displace these medications, resulting in high free fractions and increased likelihood of toxicity. The potential interaction between phenytoin and valproic acid deserves special attention. Given that phenytoin is only weakly bound to plasma proteins, it is easily displaced by valproic acid. Valproic acid can also weakly inhibit phenytoin metabolism, further increasing its free level. ${ }^{103}$ In such a situation, the clinician must rely on the free concentration of phenytoin to make dosage decisions, as the total level can falsely appear therapeutic or only slightly supratherapeutic. Although such an interaction is more likely to be encountered in elderly patients with reduced serum albumin concentrations, children can be affected. This is particularly true in critically ill children, whose total phenytoin concentrations have been proven to be unreliable for directing therapy. ${ }^{128}$

\section{Pharmacodynamics}

One aspect of pharmacology that can both complicate and facilitate the treatment of children with epilepsy is 
pharmacodynamics. Specific combinations of AEDs are recognized to result in improved seizure control and/or more side effects than would be expected via purely additive effects. Dual therapy with carbamazepine and lamotrigine can result in more severe toxicity (including nausea, vertigo, headache, and ataxia) than would be expected from inconsistently reported increases in carbamazepine epoxide. ${ }^{129}$ Although a synergistic effect of carbamazepine and valproic acid against focal onset seizures has been demonstrated, ${ }^{130,131}$ this needs to be weighed against increases in carbamazepine epoxide. ${ }^{132}$ This is particularly pertinent for children, who can experience side effects such as tiredness and nausea/vomiting at lower epoxide concentrations than their adult counterparts. ${ }^{133}$ There have also been reports of synergistic interactions between ethosuximide and valproic acid, ${ }^{134}$ lamotrigine and topiramate, ${ }^{135}$ lamotrigine and vigabatrin, ${ }^{136}$ and tiagibine and vigabatrin. ${ }^{137}$

One of the best examples of AED synergy is the interaction between lamotrigine and valproic acid. The combination of these two medications has been demonstrated to result in improved control of focal onset seizures, absence seizures, and myoclonic seizures. ${ }^{138-140}$ Such results occur in the setting of lower peak plasma concentrations of both medications versus those on monotherapy, suggesting a favorable pharmacodynamic interaction. ${ }^{103}$ However, the clinician must weigh this benefit against the increased risk of side effects. Via competition for glucuronidation, valproic acid inhibits the metabolism of lamotrigine, prolongs its half-life, and increases its plasma concentration. ${ }^{141}$ If a pediatric patient taking valproic acid is to start concomitant lamotrigine therapy, lower doses and a slower titration of lamotrigine should be prescribed to prevent serious adverse events. ${ }^{103}$

\section{Conclusion}

Epilepsy is one of the most common neurological disorders to affect children. The choice of AED depends on seizure type/electroclinical syndrome, potential adverse effects, and ease of use. Additionally, age-dependent pharmacokinetic effects and the impact of potential interactions with other medications must be considered. A close therapeutic partnership between the child and family, and the treating physician is key to successful therapy. Families should understand the goals of treatment, potential common and rare adverse effects, as well as the possible impact that other factors including age, associated medical conditions, and other concurrent medications may have on medication levels.

\section{Disclosure}

The authors report no conflicts of interest in this work.

\section{References}

1. Camfield CS, Camfield PR, Gordon K, Wirrell E, Dooley JM. Incidence of epilepsy in childhood and adolescence: a population-based study in Nova Scotia from 1977 to 1985. Epilepsia. 1996;37:19-23.

2. Wirrell EC, Grossardt BR, Wong-Kisiel LC, Nickels KC. Incidence and classification of new-onset epilepsy and epilepsy syndromes in children in Olmsted County, Minnesota from 1980 to 2004: a population-based study. Epilepsy Res. 2011;95:110-118.

3. Hamiwka LD, Singh N, Niosi J, Wirrell EC. Diagnostic inaccuracy in children referred with "first seizure": role for a first seizure clinic. Epilepsia. 2007;48:1062-1066.

4. van Donselaar CA, Stroink H, Arts WF. How confident are we of the diagnosis of epilepsy? Epilepsia. 2006;47(Suppl 1):9-13.

5. Uldall P, Alving J, Hansen LK, Kibæk M, Buchholt J. The misdiagnosis of epilepsy in children admitted to a tertiary epilepsy centre with paroxysmal events. Arch Dis Child. 2006;91:219-221.

6. Berg AT, Berkovic SF, Brodie MJ, et al. Revised terminology and concepts for organization of seizures and epilepsies: report of the ILAE Commission on Classification and Terminology, 2005-2009. Epilepsia. 2010;51:676-685.

7. Camfield P, Camfield C. Childhood epilepsy: what is the evidence for what we think and what we do? J Child Neurol. 2003;18:272-287.

8. Glauser T, Ben-Menachem E, Bourgeois B, et al. ILAE treatment guidelines: evidence-based analysis of antiepileptic drug efficacy and effectiveness as initial monotherapy for epileptic seizures and syndromes. Epilepsia. 2006;47:1094-1120.

9. Baram TZ, Mitchell WG, Tournay A, Snead OC, Hanson RA, Horton EJ. High-dose corticotropin (ACTH) versus prednisone for infantile spasms: a prospective, randomized, blinded study. Pediatrics. 1996;97: 375-379.

10. Lux AL, Edwards SW, Hancock E, et al. The United Kingdom Infantile Spasms Study comparing vigabatrin with prednisolone or tetracosactide at 14 days: a multicentre, randomised controlled trial. Lancet. 2004;364:1773-1778.

11. Hrachovy RA, Frost JD Jr, Glaze DG. High-dose, long-duration versus low-dose, short-duration corticotropin therapy for infantile spasms. J Pediatr. 1994;124:803-806.

12. Yanagaki S, Oguni H, Hayashi K, et al. A comparative study of highdose and low-dose ACTH therapy for West syndrome. Brain Dev. 1999; 21:461-467.

13. Vigevano F, Cilio MR. Vigabatrin versus ACTH as first-line treatment for infantile spasms: a randomized, prospective study. Epilepsia. 1997; 38:1270-1274.

14. Elterman RD, Shields WD, Mansfield KA, Nakagawa J. Randomized trial of vigabatrin in patients with infantile spasms. Neurology. 2001;57: 1416-1421.

15. Chiron C, Dumas C, Jambaque I, Mumford J, Dulac O. Randomized trial comparing vigabatrin and hydrocortisone in infantile spasms due to tuberous sclerosis. Epilepsy Res. 1997;26:389-395.

16. Aicardi J, Mumford JP, Dumas C, Wood S. Vigabatrin as initial therapy for infantile spasms: a European retrospective survey. Sabril IS Investigator and Peer Review Groups. Epilepsia. 1996;37: 638-642.

17. Jambaqué I, Chiron C, Dumas C, Mumford J, Dulac O. Mental and behavioural outcome of infantile epilepsy treated by vigabatrin in tuberous sclerosis patients. Epilepsy Res. 2000;38:151-160.

18. Chiron C, Marchand MC, Tran A, et al. Stiripentol in severe myoclonic epilepsy in infancy: a randomised placebo-controlled syndromededicated trial. STICLO study group. Lancet. 2000;356:1638-1642.

19. Thanh TN, Chiron C, Dellatolas G, et al. Long-term efficacy and tolerance of stiripentol in severe myoclonic epilepsy of infancy (Dravet's syndrome). Arch Pediatr. 2002;9:1120-1127. German. 
20. Kassaï B, Chiron C, Augier S, et al. Severe myoclonic epilepsy in infancy: a systematic review and a meta-analysis of individual patient data. Epilepsia. 2008;49:343-348.

21. Inoue Y, Ohtsuka Y, Oguni H, et al. Stiripentol open study in Japanese patients with Dravet syndrome. Epilepsia. 2009;50:2362-2368.

22. Eriksson AS, Nergårdh A, Hoppu K. The efficacy of lamotrigine in children and adolescents with refractory generalized epilepsy: a randomized, double-blind, crossover study. Epilepsia. 1998;39: 495-501.

23. Jensen PK. Felbamate in the treatment of Lennox-Gastaut syndrome. Epilepsia. 1994;35(Suppl 5):S54-S57.

24. Conry JA, Ng YT, Paolicchi JM, et al. Clobazam in the treatment of Lennox-Gastaut syndrome. Epilepsia. 2009;50:1158-1166.

25. Glauser TA, Levisohn PM, Ritter F, Sachdeo RC. Topiramate in Lennox-Gastaut syndrome: open-label treatment of patients completing a randomized controlled trial. Topiramate YL Study Group. Epilepsia. 2000;41(Suppl 1):S86-S90.

26. Kluger G, Glauser T, Krauss G, Seeruthun R, Perdomo C, Arroyo S. Adjunctive rufinamide in Lennox-Gastaut syndrome: a long-term, open-label extension study. Acta Neurol Scand. 2012;122:202-208.

27. Rating D, Wolf C, Bast T. Sulthiame as monotherapy in children with benign childhood epilepsy with centrotemporal spikes: a 6-month randomized, double-blind, placebo-controlled study. Sulthiame Study Group. Epilepsia. 2000;41:1284-1288.

28. Gross-Selbeck G. Treatment of "benign" partial epilepsies of childhood, including atypical forms. Neuropediatrics. 1995;26:45-50.

29. Wakai S, Ito N, Ueda D, Chiba S. Landau-Kleffner syndrome and sulthiame. Neuropediatrics. 1997;28:135-136.

30. Wirrell E, Ho AW, Hamiwka L. Sulthiame therapy for continuous spike and wave in slow-wave sleep. Pediatr Neurol. 2006;35:204-208.

31. Sato S, White BG, Penry JK, Dreifuss FE, Sackellares JC, Kupferberg HJ. Valproic acid versus ethosuximide in the treatment of absence seizures. Neurology. 1982;32:157-163.

32. Callaghan N, O'Hare J, O'Driscoll D, O’Neill B, Daly M. Comparative study of ethosuximide and sodium valproate in the treatment of typical absence seizures (petit mal). Dev Med Child Neurol. 1982;24: 830-836.

33. Glauser TA, Cnaan A, Shinnar S, et al. Ethosuximide, valproic acid, and lamotrigine in childhood absence epilepsy. $N$ Engl J Med. 362: 790-799.

34. Genton P, Guerrini R, Remy C. Piracetam in the treatment of cortical myoclonus. Pharmacopsychiatry. 1999;32(Suppl 1):49-53.

35. Koskiniemi M, Van Vleymen B, Hakamies L, Lamusuo S, Taalas J. Piracetam relieves symptoms in progressive myoclonus epilepsy: a multicentre, randomised, double blind, crossover study comparing the efficacy and safety of three dosages of oral piracetam with placebo. J Neurol Neurosurg Psychiatry. 1998;64:344-348.

36. Guerreiro MM, Vigonius U, Pohlmann H, et al. A double-blind controlled clinical trial of oxcarbazepine versus phenytoin in children and adolescents with epilepsy. Epilepsy Res. 1997;27:205-213.

37. Thilothammal N, Banu K, Ratnam RS. Comparison of phenobarbitone, phenytoin with sodium valproate: randomized, double-blind study. Indian Pediatr. 1996;33:549-555.

38. de Silva M, MacArdle B, McGowan M, et al. Randomised comparative monotherapy trial of phenobarbitone, phenytoin, carbamazepine, or sodium valproate for newly diagnosed childhood epilepsy. Lancet. 1996;347:709-713.

39. Verity CM, Hosking G, Easter DJ. A multicentre comparative trial of sodium valproate and carbamazepine in paediatric epilepsy. The Paediatric EPITEG Collaborative Group. Dev Med Child Neurol. 1995; 37:97-108.

40. Mitchell WG, Chavez JM. Carbamazepine versus phenobarbital for partial onset seizures in children. Epilepsia. 1987;28:56-60.

41. Bawden HN, Camfield CS, Camfield PR, et al. The cognitive and behavioural effects of clobazam and standard monotherapy are comparable. Canadian Study Group for Childhood Epilepsy. Epilepsy Res. 1999;33:133-143.
42. Pal DK, Das T, Chaudhury G, Johnson AL, Neville BG. Randomised controlled trial to assess acceptability of phenobarbital for childhood epilepsy in rural India. Lancet. 1998;351:19-23.

43. Forsythe I, Butler R, Berg I, McGuire R. Cognitive impairment in new cases of epilepsy randomly assigned to carbamazepine, phenytoin and sodium valproate. Dev Med Child Neurol. 1991;33:524-534.

44. Vining EP, Mellitis ED, Dorsen MM, et al. Psychologic and behavioral effects of antiepileptic drugs in children: a double-blind comparison between phenobarbital and valproic acid. Pediatrics. 1987;80: $165-174$.

45. Nieto-Barrera M, Brozmanova M, Capovilla G, et al for the Lamictal vs Carbamazepine Study Group. A comparison of monotherapy with lamotrigine or carbamazepine in patients with newly diagnosed partial epilepsy. Epilepsy Res. 2001;46:145-155.

46. Sobaniec W, Kulak W, Strzelecka J, Smigielska-Kuzia J, Boćkowski L. A comparative study of vigabatrin vs carbamazepine in monotherapy of newly diagnosed partial seizures in children. Pharmacol Rep. 2005;57: 646-653.

47. Shields WD, Saslow E. Myoclonic, atonic, and absence seizures following institution of carbamazepine therapy in children. Neurology. 1983;33:1487-1489.

48. Snead OC 3rd, Hosey LC. Exacerbation of seizures in children by carbamazepine. N Engl J Med. 1985;313:916-921.

49. Viani F, Romeo A, Viri M, et al. Seizure and EEG patterns in Angelman's syndrome. J Child Neurol. 1995;10:467-471.

50. Kochen S, Giagante B, Oddo S. Spike-and-wave complexes and seizure exacerbation caused by carbamazepine. Eur J Neurol. 2002;9:41-47.

51. Corda D, Gelisse P, Genton P, Dravet C, Baldy-Moulinier M. Incidence of drug-induced aggravation in benign epilepsy with centrotemporal spikes. Epilepsia. 2001;42:754-759.

52. Eldridge R, Stern R, Anainen M, Koerber T, Wilder BJ. "Baltic" myoclonus epilepsy: hereditary disorder of childhood made worse by phenytoin. Lancet. 1983;322:838-842.

53. Guerrini R, Dravet C, Genton P, Belmonte A, Kaminska A, Dulac O. Lamotrigine and seizure aggravation in severe myoclonic epilepsy. Epilepsia. 1998;39:508-512.

54. Tassinari CA, Dravet C, Roger J, Cano JP, Gastaut H. Tonic status epilepticus precipitated by intravenous benzodiazepine in five patients with Lennox-Gastaut syndrome. Epilepsia. 1972;13:421-435.

55. Sillanpaa M. Epilepsy in children: prevalence, disability, and handicap. Epilepsia. 1992;33:444-449.

56. Depositario-Cabacar DF, Zelleke TG. Treatment of epilepsy in children with developmental disabilities. Dev Disabil Res Rev. 2010; 239-247.

57. Sherman EM, Slick DJ, Connolly MB, Eyrl KL. ADHD, neurological correlates and health-related quality of life in severe pediatric epilepsy. Epilepsia. 2007;48:1083-1091.

58. Parisi P, Moavero R, Verrotti A, Curatolo P. Attention deficit hyperactivity disorder in children with epilepsy. Brain Dev. 2010;32:10-16.

59. Miller JM, Kustra RP, Vuong A, Hammer AE, Messenheimer JA. Depressive symptoms in epilepsy: prevalence, impact, aetiology, biological correlates and effect of treatment with antiepileptic drugs. Drugs. 2008;68:1493-1509.

60. Shellhaas RA, Joshi SM. Vitamin D and bone health among children with epilepsy. Pediatr Neurol. 2010;42:385-393.

61. Bittigau P, Sifringer M, Genz K, et al. Antiepileptic drugs and apoptotic neurodegeneration in the developing brain. Proc Natl Acad Sci US A. 2002;99:15089-15094

62. Kaindl AM, Asimiadou S, Manthey D, Hagen MV, Turski L, Ikonomidou C. Antiepileptic drugs and the developing brain. Cell Mol Life Sci. 2006;63:399-413.

63. Glier C, Dzietko M, Bittigau P, Jarosz B, Korobowicz E, Ikonomidou C. Therapeutic doses of topiramate are not toxic to the developing rat brain. Exp Neurol. 2004;187:403-409.

64. Dreifuss FE, Santilli N, Langer DH, Sweeney KP, Moline KA, Menander KB. Valproic acid hepatic fatalities: a retrospective review. Neurology. 1987;37:379-385. 
65. Bryant AE 3rd, Dreifuss FE. Valproic acid hepatic fatalities. III. US experience since 1986. Neurology. 1996;46:465-469.

66. König SA, Siemes H, Blaker F, et al. Severe hepatotoxicity during valproate therapy: an update and report of eight new fatalities. Epilepsia. 1994;35:1005-1015.

67. Dreifuss FE, Langer DH, Moline KA, Maxwell JE. Valproic acid hepatic fatalities. II. US experience since 1984. Neurology. 1989;39: 201-207.

68. Appleton RE, Farrell K, Applegarth DA, Dimmick JE, Wong LT, Davidson AG. The high incidence of valproate hepatotoxicity in infants may relate to familial metabolic defects. Can J Neurol Sci. 1990;17: $145-148$.

69. Fromenty B, Pessayre D. Inhibition of mitochondrial beta-oxidation as a mechanism of hepatotoxicity. Pharmacol Ther. 1995;67:101-154.

70. Kesterson JW, Granneman GR, Machinist JM. The hepatotoxicity of valproic acid and its metabolites in rats. I. Toxicologic, biochemical and histopathologic studies. Hepatology. 1984;4:1143-1152.

71. Shen DD, Pollack GM, Cohen ME, et al. Effect of age on the serum metabolite pattern of valproic acid in epileptic children [abstract]. Epilepsia. 1984;5:674.

72. Levy RH, Rettenmeier AW, Anderson GD, et al. Effects of polytherapy with phenytoin, carbamazepine, and stiripentol on formation of 4-enevalproate, a hepatotoxic metabolite of valproic acid. Clin Pharmacol Ther. 1990;48:225-235.

73. Schwabe MJ, Dobyns WB, Burke B, Armstrong DL. Valproate-induced liver failure in one of two siblings with Alpers disease. Pediatr Neurol. 1997; 16:337-343.

74. Delarue A, Paut O, Guys JM, et al. Inappropriate liver transplantation in a child with Alpers-Huttenlocher syndrome misdiagnosed as valproateinduced acute liver failure. Pediatr Transplant. 2000;4:67-71.

75. Njølstad PR, Skjeldal OH, Agsteribbe E, et al. Medium chain acyl-CoA dehydrogenase deficiency and fatal valproate toxicity. Pediatr Neurol. 1997;16:160-162.

76. Dhamija R, Gavrilova RH, Wirrell EC. Valproate-induced worsening of seizures: clue to underlying diagnosis. J Child Neurol. 2011;26: 1319-1321.

77. Lheureux PE, Penaloza A, Zahir S, Gris M. Science review: carnitine in the treatment of valproic acid-induced toxicity - what is the evidence? Crit Care. 2005;9:431-440.

78. Edwards SG, Hubbard V, Aylett S, Wren D. Concordance of primary generalised epilepsy and carbamazepine hypersensitivity in monozygotic twins. Postgrad Med J. 1999;75:680-681.

79. Hung SI, Chung WH, Jee SH, et al. Genetic susceptibility to carbamazepine-induced cutaneous adverse drug reactions. Pharmacogenet Genomics. 2006;16:297-306.

80. Anderson GD. Children versus adults: pharmacokinetic and adverseeffect differences. Epilepsia. 2002;43(Suppl 3):53-59.

81. Pellock JM. Felbamate. Epilepsia. 1999;40(Suppl 5):S57-S62.

82. Popovic M, Nierkens S, Pieters R, Uetrecht J. Investigating the role of 2-phenylpropenal in felbamate-induced idiosyncratic drug reactions. Chem Res Toxicol. 2004;17:1568-1576.

83. Willmore LJ, Abelson MB, Ben-Menachem E, Pellock JM, Shields WD Vigabatrin: 2008 update. Epilepsia. 2009;50:163-173.

84. Jammoul F, Degardin J, Pain D, et al. Taurine deficiency damages photoreceptors and retinal ganglion cells in vigabatrin-treated neonatal rats. Mol Cell Neurosci. 2010;43:414-421.

85. Dracopoulos A, Widjaja E, Raybaud C, Westall CA, Snead OC 3rd. Vigabatrin-associated reversible MRI signal changes in patients with infantile spasms. Epilepsia. 2010;51:1297-1304.

86. Handoko KB, Souverein PC, van Staa TP, et al. Risk of aplastic anemia in patients using antiepileptic drugs. Epilepsia. 2006;47: 1232-1236.

87. Camfield C, Camfield P, Smith E, Tibbles JA. Asymptomatic children with epilepsy: little benefit from screening for anticonvulsant-induced liver, blood, or renal damage. Neurology. 1986;36:838-841.

88. Hauser WA. The prevalence and incidence of convulsive disorders in children. Epilepsia. 1994;35(Suppl 2):S1-S6.
89. Ben-Ari Y. Excitatory actions of gaba during development: the nature of the nurture. Nature Reviews. 2002;3:728-739.

90. Yamada J, Okabe A, Toyoda H, Kilb W, Luhmann HJ, Fukuda A. $\mathrm{Cl}^{-}$uptake promoting depolarizing GABA actions in immature rat neocortical neurones is mediated by NKCC1. J Physiol. 2004;557: 829-841.

91. Dzhala VI, Talos DM, Sdrulla DA, et al. NKCC1 transporter facilitates seizures in the developing brain. Nat Med. 2005;11:1205-1213.

92. Veliskova J, Moshe SL. Update on the role of substantia nigra pars reticulata in the regulation of seizures. Epilepsy Curr. 2006;6: $83-87$.

93. Ek CJ, Dziegielewska KM, Habgood MD, Saunders NR. Barriers in the developing brain and Neurotoxicology. Neurotoxicology. December 19, 2011. [Epub ahead of print.]

94. Yokoi T. Essentials for starting a pediatric clinical study (1): Pharmacokinetics in children. J Toxicol Sci. 2009;34(Suppl 2):SP307-SP312.

95. Anderson GD, Lynn AM. Optimizing pediatric dosing: a developmental pharmacologic approach. Pharmacotherapy. 2009;29:680-690.

96. Milsap RL, Jusko WJ. Pharmacokinetics in the infant. Environ Health Perspect. 1994;102(Suppl 11):107-110.

97. Cvetkovic M, Leake B, Fromm MF, Wilkinson GR, Kim RB. OATP and P-glycoprotein transporters mediate the cellular uptake and excretion of fexofenadine. Drug Metab Disp. 1999;27:866-871.

98. Chapman K, Rho JM. Pediatric Epilepsy Case Studies: From Infancy and Childhood Through Adolescence. Boca Raton: CRC Press; 2009.

99. Perucca E. Clinical pharmacokinetics of new-generation antiepileptic drugs at the extremes of age. Clin Pharmacokinet. 2006;45:351-363.

100. Woo E, Chan YM, Yu YL, Chan YW, Huang CY. If a well-stabilized epileptic patient has a subtherapeutic antiepileptic drug level, should the dose be increased? A randomized prospective study. Epilepsia. 1988;29:129-139.

101. St Louis EK. Monotherapy to polytherapy: antiepileptic drug conversions through the spectrum of epilepsy care. Curr Neuropharmacol. 2009; 7:75-76.

102. Ramos-Lizana J, Aguilera-López P, Aguirre-Rodríguez J, CassinelloGarcía E. Response to sequential treatment schedules in childhood epilepsy: risk for development of refractory epilepsy. Seizure. 2009; 18:620-624.

103. Patsalos PN, Fröscher W, Pisani F, van Rijn CM. The importance of drug interactions in epilepsy therapy. Epilepsia. 2002;43:365-385.

104. Patsalos PN. Pharmacokinetic and pharmacodynamic interactions: principles and interpretative pitfalls. Epileptologia. 1998;6:9-19.

105. Spatzenegger M, Jaeger W. Clinical importance of hepatic cytochrome P450 in drug metabolism. Drug Metab Rev. 1995;27:397-417.

106. Kimura M, Ieiri I, Mamiya K, Urae A, Higuchi S. Genetic polymorphism of cytochrome P450s, CYP2C19, and CYP2C9 in a Japanese population. Ther Drug Monit. 1998;20:243-247.

107. Ninomiya H, Mamiya K, Matsuo S, Ieiri I, Higuchi S, Tashiro N. Genetic polymorphism of the CYP2C subfamily and excessive serum phenytoin concentration with central nervous system intoxication. Ther Drug Monit. 2000;22:230-232.

108. May T, Rambeck B. Serum concentrations of valproic acid: influence of dose and comedication. Ther Drug Monit. 1985;7:387-390.

109. Sachdeo RC, Sachdeo SK, Walker SA, Kramer LD, Nayak RK, Doose DR. Steady-state pharmacokinetics of topiramate and carbamazepine in patients with epilepsy during monotherapy and concomitant therapy. Epilepsia. 1996;37:774-780.

110. Rambeck B, Wolf P. Lamotrigine clinical pharmacokinetics. Clin Pharmacokinet. 1993;25:433-443.

111. Bartoli A, Guerrini R, Belmonte A, Alessandri MG, Gatti G, Perucca E. The influence of dosage, age, and comedication on steady state plasma lamotrigine concentrations in epileptic children: a prospective study with preliminary assessment of correlations with clinical response. Ther Drug Monit. 1997;19:252-260.

112. Brodie MJ, Perucca E, Ryvlin P, Ben-Menachem E, Meencke HJ. Comparison of levetiracetam and controlled-release carbamazepine in newly diagnosed epilepsy. Neurology. 2007;68:402-408. 
113. Majowski J. Antiepileptic and nonantiepileptic drug interactions. Epileptologia. 1998;6:55-73.

114. Prichard PJ, Walt RP, Kitchingman GK, et al. Oral phenytoin pharmacokinetics during omeprazole therapy. Br J Clin Pharmacol. 1987;24:543-545.

115. Hetzel DJ, Bochner F, Hallpike JF, Shearman DJ, Hann CS. Cimetidine interaction with phenytoin. Br Med J (Clin Res Ed). 1981;282:1512.

116. Monaco F, Cicolin A. Interactions between anticonvulsant and psychoactive drugs. Epilepsia. 1999;40(Supp1 10):S71-S76.

117. Nelson MH, Birnbaum AK, Remmel RP. Inhibition of phenytoin hydroxylation in human liver microsomes by several selective serotonin re-uptake inhibitors. Epilepsy Res. 2001;44:71-82.

118. Grimsley SR, Jann MW, Carter JG, D’Mello AP, D’Souza MJ. Increased carbamazepine plasma concentrations after fluoxetine coadministration. Clin Pharmacol Ther. 1991;50:10-15.

119. Kaufman KR, Gerner R. Lamotrigine toxicity secondary to sertraline. Seizure. 1998;7:163-165.

120. Blum RA, Wilton JH, Hilligoss DM, et al. Effect of fluconazole on the disposition of phenytoin. Clin Pharmacol Ther. 1991;49:420-425.

121. Carranco E, Kareus J, Co S, Peak V, Al-Rajeh S. Carbamazepine toxicity induced by concurrent erythromycin therapy. Arch Neurol. $1985 ; 42: 187-188$.

122. O'Connor NK, Fris J. Clarithromycin-carbamazepine interaction in a clinical setting. J Am Board Fam Pract. 1994;7:489-492.

123. Roby CA, Anderson GD, Kantor E, Dryer DA, Burstein AH. St John's Wort: effect on CYP3A4 activity. Clin Pharmacol Ther. 2000;67: 451-457.

124. Reddy DS. Clinical pharmacokinetic interactions between antiepileptic drugs and hormonal contraceptives. Expert Rev Clin Pharmacol. 2010; 3:183-192.

125. Vajda FJ, Hitchcock AA, Graham J, O’Brien TJ, Lander CM, Eadie MJ. The teratogenic risk of antiepileptic drug polytherapy. Epilepsia. 2010;51:805-810.

126. Magnusson MO, Dahl ML, Cederberg J, Karlsson MO, Sandström R. Pharmacodynamics of carbamazepine-mediated induction of CYP3A4, CYP1A2, and Pgp as assessed by probe substrates midazolam, caffeine, and digoxin. Clin Pharmacol Ther. 2008;84:52-62.

127. Patsalos PN. Properties of antiepileptic drugs in the treatment of idiopathic generalized epilepsies. Epilepsia. 2005;46(Suppl 9): $140-148$.
128. Wolf GK, McClain CD, Zurakowski D, Dodson B, McManus ML. Total phenytoin concentrations do not accurately predict free phenytoin concentrations in critically ill children. Pediatr Crit Care Med. 2006; 7:434-439; quiz 440.

129. Besag FM, Berry DJ, Pool F, Newbery JE, Subel B. Carbamazepine toxicity with lamotrigine: pharmacokinetic or pharmacodynamic interaction? Epilepsia. 1998;39:183-187.

130. Gupta AK, Jeavons PM. Complex partial seizures: EEG foci and response to carbamazepine and sodium valproate. J Neurol Neurosurg Psychiatry. 1985;48:1010-1014.

131. Ketter TA, Pazzaglia PJ, Post RM. Synergy of carbamazepine and valproic acid in affective illness: case report and review of the literature. J Clin Psychopharmacol. 1992;12:276-281.

132. Rambeck B, May T, Juergens U. Serum concentrations of carbamazepine and its epoxide and diol metabolites in epileptic patients: the influence of dose and comedication. Ther Drug Monit. 1987;9: 298-303.

133. Rambeck B. Antiepileptic drug interactions in polytherapy. Epileptologia. 1998;2:43-53.

134. Rowan AJ, Meijer JW, de Beer-Pawlikowski N, van der Geest P, Meinardi H. Valproate-ethosuximide combination therapy for refractory absence seizures. Arch Neurol. 1983;40:797-802.

135. Stephen LJ, Sills GJ, Brodie MJ. Lamotrigine and topiramate may be a useful combination. Lancet. 1998;351:958-959.

136. Stolarek I, Blacklaw J, Forrest G, Brodie MJ. Vigabatrin and lamotrigine in refractory epilepsy. $J$ Neurol Neurosurg Psychiatry. 1994;57:921-924.

137. Leach JP, Brodie MJ. Synergism with GABAergic drugs in refractory epilepsy. Lancet. 1994;343:1650.

138. Pisani F, Di Perri R, Perucca E, Richens A. Interaction of lamotrigine with sodium valproate. Lancet. 1993;341:1224.

139. Ferrie CD, Robinson RO, Knott C, Panayiotopoulos CP. Lamotrigine as an add-on drug in typical absence seizures. Acta Neurol Scand. 1995;91:200-202.

140. Ferrie CD, Panayiotopoulos CP. Therapeutic interaction of lamotrigine and sodium valproate in intractable myoclonic epilepsy. Seizure. 1994;3:157-159.

141. Yuen AW, Land G, Weatherley BC, Peck AW. Sodium valproate acutely inhibits lamotrigine metabolism. Br J Clin Pharmacol. 1992; 33:511-513.
Drug, Healthcare and Patient Safety

\section{Publish your work in this journal}

Drug, Healthcare and Patient Safety is an international, peer-reviewed open-access journal exploring patient safety issues in the healthcare continuum from diagnostic and screening interventions through to treatment, drug therapy and surgery. The journal is characterized by the rapid reporting of reviews, original research, clinical, epidemiological and

\section{Dovepress}

post-marketing surveillance studies, risk management, health literacy and educational programs across all areas of healthcare delivery. The manuscript management system is completely online and includes a very quick and fair peer-review system. Visit http://www.dovepress.com/ testimonials.php to read real quotes from published authors. 